\title{
A NECESSIDADE DO IEEE WOMEN IN ENGINEERING UFJF PARA A PERMANÊNCIA DE MULHERES NOS CURSOS DE ENGENHARIA E CIÊNCIAS EXATAS
}

\begin{abstract}
Mariana Larissa Antunes da Costa - mariana.antunes@ engenharia.ufjf.br
Ana Beatriz Baldow Almeida - ana.baldow@engenharia.ufjf.br

Daiana Carmo Coelho - daiana.coelho@engenharia.ufjf.br

Letícia Costa Martins - leticia.martins@engenharia.ufjf.br

Janaína Gonçalves de Oliveira - janaina.oliveira@ufjf.edu.br

Universidade Federal de Juiz de Fora, Faculdade de Engenharia

Rua José Lourenço Kelmer, s/n - Campus Universitário - Bairro São Pedro

36.036-900 - Juiz de Fora - Minas Gerais
\end{abstract}

Resumo: Este trabalho tem como objetivo explicar a importância do grupo de afinidade IEEE Women in Engineering da Universidade Federal de Juiz de Fora (UFJF), por meio de seus projetos e inciativas, para manutenção de mulheres nas áreas de STEM (Science, Technology, Engineering and Maths - Ciências, Tecnologias, Engenharias e Matemáticas, em tradução livre) e o ingresso de meninas nessas áreas que são consideradas historicamente como masculinas. O projeto tem iniciativas para crianças, jovens e adultos, além de já ter atingido mais de 30 mil pessoas nas suas ações e atividades.

Palavras-chave: Mulheres na Engenharia. Empoderamento feminino. Engenharias. STEM.

\section{INTRODUÇÃO}

As mulheres, em sua maioria, desde os tempos mais antigos, não são motivadas ou inspiradas a seguirem áreas ligadas a ciências, engenharias e tecnologias, ficando responsáveis pelo cuidado domiciliar e pela família ou por profissões ligadas a isso (HIRATA, 2002). De acordo com a Federação Nacional dos Engenheiros (2015), a partir do Perfil Ocupacional dos Profissionais da Engenharia no Brasil, é nítido que a participação de mulheres em áreas de STEM (Science, Technology, Engineering and Maths - Ciências, Tecnologias, Engenharias e Matemáticas, em tradução livre) vem aumentando a cada ano. Porém, ainda em número bem inferior ao comparado com homens nas mesmas áreas. Além disso, o seu retorno financeiro é menor ao ser comparado com o salário dos colegas do sexo masculino, de acordo com a Pesquisa FAPESP (2020).

De acordo com pesquisas, como a exposta pela Revista DomTotal, em 2018, muitas vezes, as meninas e mulheres não ingressam em áreas de STEM por falta de incentivo ou por acharem que elas não pertencem a essa grande área pelo simples fato de serem do sexo feminino, visto que a maioria dos grandes nomes divulgados nessas áreas são, de fato, de homens.

Diante disso, surgem diversas iniciativas para trazer e manter meninas e mulheres nessas áreas. Dentre essas iniciativas, existe o IEEE Women in Engineering (WIE) UFJF (Universidade Federal de Juiz de Fora), um dos grupos IEEE WIE do Conselho Brasil do IEEE, 
com a missão de motivar, empoderar e instruir garotas em STEM, principalmente em Engenharias.

Esse artigo visa expor os bons resultados providos da atuação do IEEE Women in Engineering UFJF, com o auxílio de seus voluntários, no desenvolvimento de ações, projetos e eventos com base na importância de discutir, e trabalhar, essa temática $\mathrm{O}$ mesmo se divide em seções que contextualizam o Instituto de Engenheiros Eletricistas e Eletrônicos com o Women in Engineering, e consequentemente sobre o Ramo Estudantil IEEE UFJF e o IEEE WIE UFJF que é o foco dessa documentação. Será apresentado, também, acerca da organização do grupo e, em seguida, a apresentação e descrição dos projetos desenvolvimentos.

\section{O INSTITUTO DE ENGENHEIROS ELETRICISTAS E ELETRÔNICOS E O WOMEN IN ENGINEERING}

O Institute of Electrical and Electronics Engineers - IEEE é a maior sociedade técnica e profissional do mundo em número de membros. De acordo com o Reporte Anual do IEEE de 2019, a sociedade congrega mais de 419.000 associados, entre engenheiros, cientistas, pesquisadores e outros profissionais, em cerca de 160 países. Compõe-se de 10 regiões, 39 sociedades técnicas, 7 conselhos técnicos, e mais de 2400 capítulos de sociedades e mais de 340 seções.

O Instituto realiza os principais congressos, cria padrões e normas e é responsável por aproximadamente $30 \%$ das publicações científicas na área de Engenharia Elétrica, Computação e Tecnologia. O IEEE é uma entidade que colabora no incremento da prosperidade técnicocientífica mundial e é líder no avanço da tecnologia, estimulando a inovação tecnológica, beneficiando as carreiras de seus membros e promovendo sua integração em uma comunidade global de profissionais de Engenharia Elétrica e áreas correlatas.

Atuando junto a essa organização, o IEEE WIE é um dos líderes mundiais em mudar a cara da engenharia. De acordo com o site oficial do IEEE WIE, sua rede global conecta quase 20.000 membros em mais de 100 países para promover as mulheres em tecnologia em todos os momentos de sua vida e carreira. Os membros do IEEE WIE adquirem mentores influentes e fazem a diferença para o benefício da humanidade. O objetivo da iniciativa é facilitar o recrutamento e a retenção de mulheres em disciplinas técnicas em todo o mundo.

\subsection{O Ramo Estudantil IEEE UFJF}

De acordo com o site oficial e PIRES et al (2018), o núcleo surgiu no início da década de 90 como um dos pilares necessários à implementação de cursos de pós-graduação em Engenharia Elétrica na Universidade. Uma vez que as bibliotecas da UFJF não dispunham, àquela época, de literatura técnico-científica de qualidade para apoio às atividades de Pesquisa e Desenvolvimento, a criação de um Ramo Estudantil IEEE foi vista como um facilitador para o acesso às melhores e mais atuais publicações científicas, tendo em vista que através do Ramo todos os periódicos do IEEE poderiam ser adquiridos por valor quinze vezes inferior ao preço corrente.

Em 1991 o Ramo Estudantil IEEE UFJF foi de fato criado. É importante destacar que os periódicos adquiridos por intermédio do Ramo Estudantil foram elementos fundamentais no credenciamento concedido pela CAPES para instalação do Curso de Mestrado em Engenharia Elétrica da UFJF, em 1998.

Atualmente o Ramo Estudantil IEEE UFJF constitui espaço privilegiado para complementar a formação dos engenheiros, pois aborda questões, atividades e competências 
normalmente não trabalhadas em sala de aula. Com atividades que já integram o calendário de eventos da UFJF, e sempre agregando inovações e ações à sua responsabilidade, o Ramo Estudantil da UFJF tornou-se imprescindível ao curso de Engenharia Elétrica, podendo ser considerado também um dos responsáveis pela boa formação dos alunos.

\section{O IEEE WOMEN IN ENGINEERING UFJF}

Iniciando suas atividades no ano de 2004, sendo assim o primeiro IEEE WIE do Brasil, o IEEE WIE UFJF tem como objetivo incentivar e ajudar a todas as meninas que possuam a vontade de se tornarem engenheiras, ou cientistas, a prosseguir nas áreas tecnológicas e a criar uma comunidade de mulheres e homens que trabalhem coletivamente, usando seus diversos talentos e aptidões, para inovar em benefício da humanidade.

O grupo atua em parceria com outros Grupos de Afinidades, Capítulos Técnicos e Segmentos Estudantis no desenvolvimento de projetos de cunho humanitário, em sua maioria inspirados nos 17 Objetivos de Desenvolvimento Sustentável (ODS) da ONU, que beneficiem a comunidade acadêmica de Juiz de Fora e região. Com nossos projetos conseguimos atingir os seguintes objetivos: Objetivo 4: Assegurar a educação inclusiva, equitativa e de qualidade, e promover oportunidades de aprendizagem ao longo da vida para todos; Objetivo 5: Alcançar a igualdade de gênero e empoderar todas as mulheres e meninas; Objetivo 10: Reduzir a desigualdade dentro dos países e entre eles.

Figura 1 - Parte da equipe do IEEE WIE UFJF

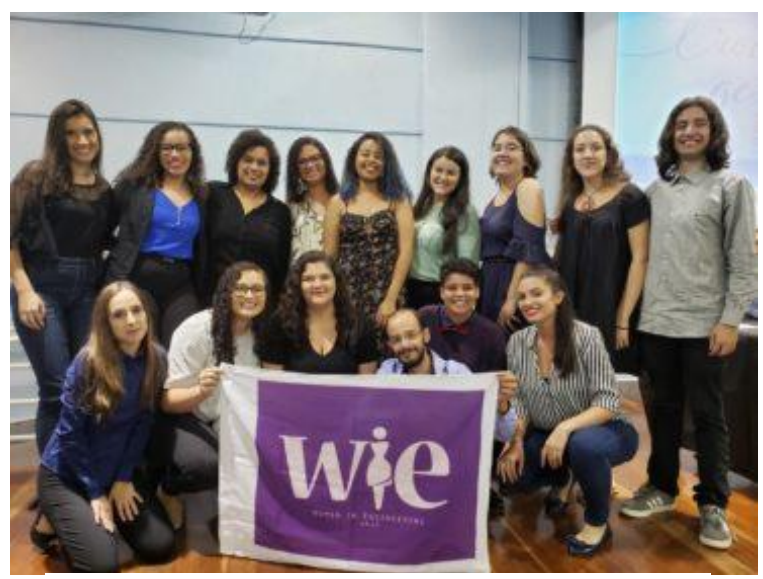

Fonte: Os autores, 2019.

\subsection{Organização}

O Conselho Consultivo do IEEE WIE UFJF é formado pela Presidente, Vice-presidente, Secretária, Tesoureira e Webmaster. O grupo é orientado por uma professora também membro IEEE, que o auxilia com seus projetos e suas iniciativas internas e externas à Universidade, além de ser mediadora do núcleo com a Faculdade de Engenharia.

A divisão de liderança de projetos é feita para que sejam estimuladas competências naquelas que tenham interesse em assumir posições de criação, desenvolvimento, organização e manutenção de projetos, o que colabora para um futuro no mercado de trabalho, incentiva o prosseguimento dos trabalhos e novas capacidades pessoais. Atualmente, existe a colaboração de 33 voluntários, os quais participam em um ou mais projetos, tendo essa relação definida no início de cada semestre letivo. 


\section{ATIVIDADES REALIZADAS PELO IEEE WIE UFJF}

O IEEE WIE UFJF realiza projetos educacionais, humanitários e tecnológicos, a fim de colaborar com a sociedade em geral e motivar mulheres nas áreas já enunciadas. Atualmente o núcleo possui 5 projetos ativos. A duração inicial de cada projeto é definida pelo Conselho do grupo, juntamente com a liderança de cada ação. Além disso, a recorrência de cada atividade é definida por cada equipe de projeto, de acordo com as demandas e o planejamento semestral. Existem projetos que são realizados dentro da comunidade acadêmica e outros que são desenvolvidos junto à comunidade externa à UFJF, em parcerias com outros núcleos estudantis da universidade e com outras organizações da cidade de Juiz de Fora. Para se manterem ativos, todos os projetos são orçados para terem o menor investimento possível, visto que os recursos são advindos de doações e de valores recebidos pela venda de camisas, canecas e bottons. Os projetos serão apresentados nos itens seguintes.

\subsection{Circuito Científico}

Nascido em 2017, o projeto Circuito Científico tem o intuito de levar às escolas da região uma nova proposta de ensino das Ciências, visando contribuir no interesse dos alunos pelas áreas de exatas, na didática dos professores, na aproximação da escola à universidade e na estimulação da curiosidade e senso crítico da comunidade.

Utilizam-se materiais de baixo custo, os quais são levados até as redes de ensino, de preferência com um laboratório de ciências acessível: alunos de diversas faixas etárias têm a oportunidade de realizar experimentos com materiais presentes em nosso cotidiano, e entender as diversas formas em que a ciência se faz presente em nossas vidas.

A cada visita tem-se a oportunidade de engajar crianças e adolescentes no estudo das ciências, estimulando senso crítico e novas percepções de mundo, colaboramos com professores na elaboração de aulas práticas e no aumento do interesse dos alunos. Além disso, por se tratar de um grupo composto em sua maioria por mulheres, estimula novas mediadoras das mais diversas áreas presentes nas exatas na prática STEM. Ele já atingiu mais de 4500 crianças e adolescentes na cidade de Juiz de Fora e região.

O Circuito Científico, desde 2018, tornou-se Projeto de Extensão da UFJF, aumentando as iniciativas em escolas de Juiz de Fora e região, impactando cada vez mais crianças e adolescentes. Além disso, em 2018 conquistou o prêmio de melhor projeto da América Latina e, em 2019, o de um dos melhores projetos mundiais dentro das iniciativas do IEEE.

\subsection{De Engenheira Para Futura Engenheira}

Como um dos objetivos do IEEE WIE UFJF é inspirar meninas e mulheres a iniciarem o continuarem suas carreiras em áreas de STEM, o projeto De Engenheira Para Futura Engenheira conta com a divulgação de fotos e textos de mulheres graduandas e graduadas em Engenharia nas redes sociais do IEEE WIE UFJF. A iniciativa existe desde 2018.

Nas postagens, que antes eram feitas de acordo com a disponibilidade e desde abril deste ano são realizadas semanalmente, contam um pouco de suas histórias e experiências nos diversos cursos da Engenharia ofertados pelo campus, além da divulgação dos obstáculos e caminhos percorridos por ex-alunas e suas carreiras atuais. Ocorreram também edições com professoras da Faculdade de Engenharia e das Ciências Exatas da UFJF. Além disso, conta 
também com bate papos com ex-membros do WIE sobre o mercado de trabalho na indústria e na academia. Atingindo mais de 20 mil pessoas, o projeto foi premiado nos concursos nacionais do IEEE no ano de 2019.

\subsection{Motiva WIE}

Ativo desde 2018, o projeto Motiva WIE tem como principal objetivo apoiar e acolher as estudantes de engenharia e demais cursos durante a graduação. $O$ grupo realiza ações por toda a faculdade, desde eventos a bilhetes de incentivo se manterem na universidade, visto que os cursos de engenharia são historicamente masculinos. A "Caixinha WIE" é uma iniciativa para compartilhar objetos úteis para o dia-a-dia das estudantes, como material de higiene pessoal e remédios, espalhados pelos banheiros da Universidade.

Outra iniciativa deste projeto é a Semana das Mulheres, a qual foi realizada nos anos 2019 e 2020, em meados do mês de maio, com objetivo de comemorar o Dia Internacional das Mulheres. Este evento reúne diversos profissionais para realizar atividades, palestras, workshops e treinamentos voltados para o público feminino, com temas de desenvolvimento pessoal, mercado de trabalho, liderança e STEM.

Uma das atividades de maior impacto do projeto foi o "Mamãe WIE", que estudou a situação de mulheres que foram ou são mães durante a graduação. Tal ação teve o objetivo traçar características dessas mulheres, como seus cursos e contexto social, além de colher depoimentos. Depois, foi realizado um piquenique com todas as mães que se propuseram a participar, onde alguns depoimentos foram filmados a fim de criar-se um vídeo sobre o tema para o Dia das Mães de 2019, o qual obteve grande repercussão. Com o alcance de mais de 7 mil pessoas, esta iniciativa trouxe para o IEEE WIE UFJF um prêmio nacional e um internacional nos concursos de projetos do IEEE.

Durante o período de isolamento social causado pela pandemia de COVID-19, com as atividades presenciais suspensas, o Motiva WIE ofereceu uma ação on-line, via Google Meet, com uma profissional de psicologia para promover uma atividade de integração para motivar os membros do IEEE WIE UFJF.

\subsection{Mutirão Tecnológico}

O Mutirão Tecnológico, ativo desde final de 2018, é um projeto que busca devolver às mulheres em estado de vulnerabilidade social a autoconfiança, dando início a um processo crescente de desenvolvimento de autonomia para superar as barreiras criadas por conta de gênero e/ou posição socioeconômica e trazer para o cotidiano conhecimentos técnicos aprendidos na vida acadêmica. Ele atende aos ODS 5 que visa igualdade de gênero e ao ODS 10 que busca diminuir as desigualdades sociais.

Para cada público alvo, uma abordagem diferente é elaborada, pensando nas necessidades e interesses dos afetados pelo projeto. Na Casa da Mulher de Juiz de Fora, instituição municipal que recebe mulheres vítimas de violência doméstica, foi ministrado um workshop de Instalações Elétricas Básicas, abordando questões práticas como troca da resistência de chuveiro, a construção de uma extensão elétrica e o funcionamento de um disjuntor. Com isso, foi possível abordar conceitos físicos como tensão, corrente, potência e resistência. A exposição teórica também tratou de tópicos como medidas de segurança, dicas de economia de energia e como entender a conta de luz.

Essa iniciativa tornou-se um Projeto de Extensão da UFJF em 2020, o qual desenvolverá um aplicativo com informações, vídeos e tutoriais sobre pequenos reparos caseiros que tenham relação com as engenharias, além de potencializar os workshops fornecidos pelo grupo. Ainda em 2020, o projeto recebeu premiação nos concursos nacionais de projetos do IEEE. 


\subsection{WIEtech}

O WIEtech nasceu da defasagem de ensino prático preparatório para o mercado de trabalho e cotidiano presente nas Universidades, que impacta principalmente as mulheres que já carregam uma bagagem de preconceito decorrente da área. O projeto propõe treinamentos e workshops voltados para capacitar não só os integrantes do IEEE WIE UFJF como de toda a Universidade.

O primeiro treinamento consistiu num mini-curso de Linguagem de Programação, cujo domínio vem se tornando grande diferencial no mercado de trabalho. A Linguagem $\mathrm{C}$ foi a primeira a ser abordada, mas logo outros módulos como Linguagem Python e $\mathrm{C}++$ foram introduzidos.

Com o intuito de difundir a LIBRAS na sociedade acadêmica, a fim de motivar e desenvolver a comunicação com a comunidade surda, algo que geralmente não é incentivado nas escolas, a segunda ação foi a Oficina de LIBRAS, ministrado em parceria com a Faculdade de Letras LIBRAS da UFJF.

Durante a II Semana da Mulher, iniciativa do projeto Motiva WIE, houve também o treinamento de Krav Maga, arte marcial de defesa pessoal israelense, exclusivamente para o público feminino. Além disso, pelo projeto também houve um minicurso de Matlab, software muito utilizado nas engenharias e que não é efetivamente ensinado nos cursos. Ainda em 2020, o projeto recebeu premiação nos concursos nacionais de projetos nacionais do IEEE.

Figura 2 - Treinamento de Matlab.

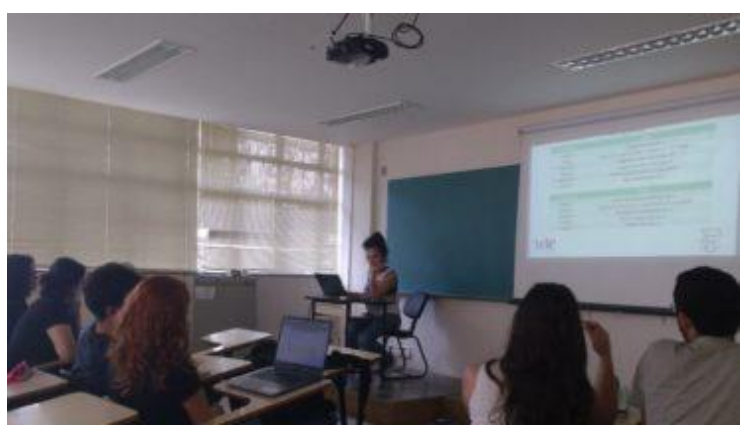

Fonte: Os autores, 2020.

Figura 4 - Atividade do Circuito Científico

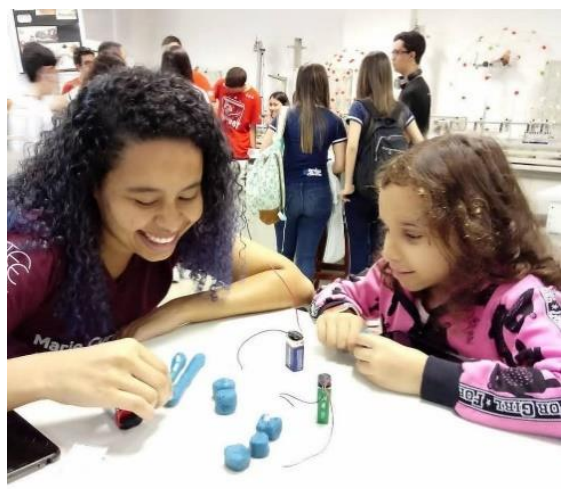

Fonte: Os autores, 2019.
Figura 3 - Workshop do Mutirão Tecnológico.

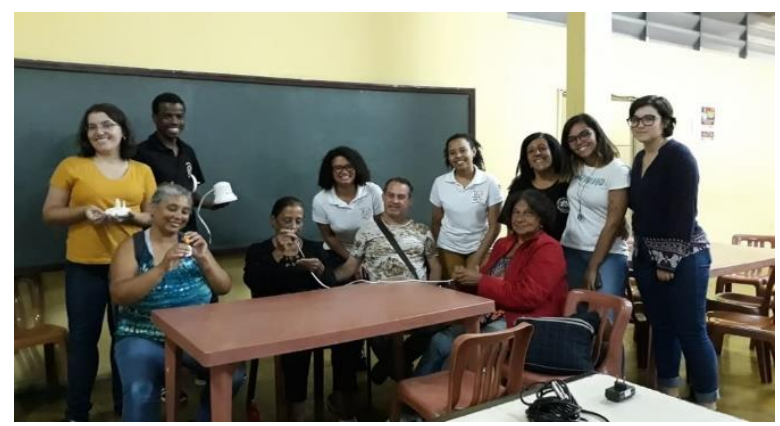

Fonte: Os autores, 2019.

Figura 5 - Palestra da I Semana das Mulheres

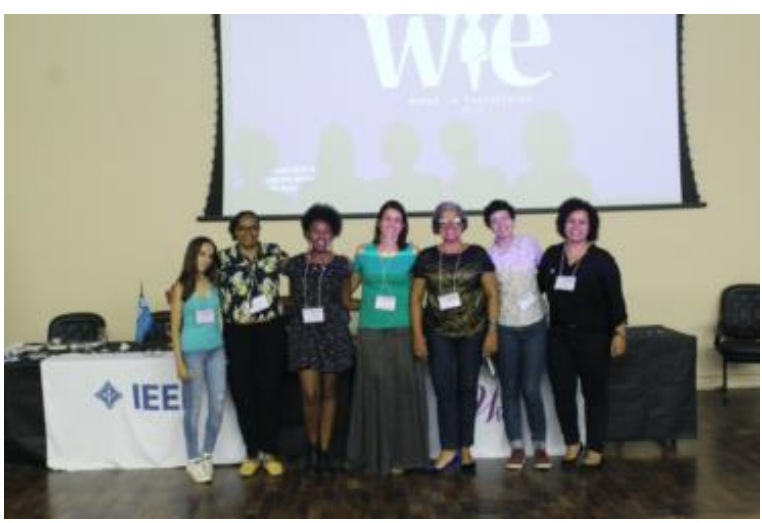

Fonte: Os autores, 2019. 


\section{CONSIDERAÇÕES FINAIS}

Iniciativas como a proposta pelo IEEE Women in Engineering UFJF são importantes e extremamente necessárias para o incentivo e manutenção de meninas e mulheres nas áreas de STEM. Além disso, traz uma grande experiência de gestão para os membros do grupo, cultivando lideranças e envolvimento com as questões de gênero que geralmente não são discutidas nas áreas de Engenharia. Os projetos desenvolvidos pelo núcleo trazem grandes impactos tanto para a vida acadêmica como para a futura vida profissional das mulheres que os acompanham, quebrando, assim estigmas tão profundos na sociedade.

Por fim, propõe-se que profissionais das áreas de STEM incentivem, promovam e visibilizem atividades para que, cada vez mais, possam existir mulheres que tenham mais notoriedade nesses espaços.

\section{Agradecimentos}

Agradecemos à Universidade Federal de Juiz de Fora, à Faculdade de Engenharia, ao Conselho Brasil do IEEE, à Seção Minas, ao Ramo Estudantil IEEE UFJF, às professoras parceiras do IEEE WIE UFJF e a todos os seus membros.

\section{REFERÊNCIAS}

DOMTOTAL. As mulheres fazem a diferença na engenharia. Disponível em: https://domtotal.com/noticia/1238975/2018/03/as-mulheres-fazem-a-diferenca-naengenharia/. Acesso em: 20 set. 2020.

IEEE WIE. Who we are. Disponível em: https://wie.ieee.org/. Acesso em: 20 set. 2020.

IEEE. Annual Report 2019. Disponível em: https://www.ieee.org/content/dam/ieeeorg/ieee/web/org/corporate-communications/annual-report/2019AnnualReport/2019-ieeeannual-report-final.pdf. Acesso em: 20 set. 2020.

FAPESP. Salário no emprego formal em engenharia para mulheres e homens no Brasil. 2020. Disponível em: https://revistapesquisa.fapesp.br/2020/03/05/salario-no-empregoformal-em-engenharia-para-mulheres-e-homens-no-brasil1/. Acesso em: 27 de maio de 2020.

HIRATA, H. Globalização e divisão sexual do trabalho. Cadernos Pagu, Campinas. 2001.

ONU. Conheça os novos 17 ODSs da ONU. Disponível em: $<$ https://nacoesunidas.org/conheca-os-novos-17-objetivos-de-desenvolvimento-sustentavelda-onu/amp/>. Acesso em: 27 de maio de 2020.

PIRES, Carlos Alexandre de Almeida et al. A importância dos trabalhos realizados pelo Ramo Estudantil IEEE UFJF na formação de voluntários e no desenvolvimento da Universidade. In: 
XLVII Congresso Brasileiro de Educação em Engenharia e II Simpósio Internacional de Educação em Engenharia da ABENGE, 2019, Ceará. Anais. Fortaleza, 2019.

RAMO ESTUDANTIL IEEE UFJF. Women in Engineering. Disponível em: <https://edu.ieee.org/br-ufjf/grupos-de-afinidade/wie/>. Acesso em: 27 de maio de 2020.

SEESP. Perfil Ocupacional dos Profissionais da Engenharia no Brasil. 2015. Disponível em: 〈http://www.seesp.org.br/site/images/documentos/PerfilFNE_net.pdf>. Acesso em: 27 de maio de 2020.

\section{THE NECESSITY OF THE IEEE WOMEN IN ENGINEERING UFJF FOR THE PERMANENCE OF WOMEN IN THE ENGINEERING AND EXACT SCIENCES COURSES}

Abstract: This work aims at explaining the importance of the IEEE Women in Engineering Affinity Group at the Federal University of Juiz de Fora (UFJF), through their projects and initiatives, for the maintenance of women in the areas of STEM (Science, Technology, Engineering and Maths) and the entry of girls in these areas that are historically considered to be male. The project has initiatives for children, youth and adults, in addition to reaching more than 30 thousand people in its actions and activities.

Keywords: Women in Engineering. Female empowerment. Engineering. STEM. 